\title{
Type II collagen as specific marker for mesenchymal chondrosarcomas compared to other small cell sarcomas of the skeleton
}

\author{
Susanna Müller, ${ }^{1, *}$, Stephan Söder ${ }^{1, *}$, André M Oliveira², Carrie Y Inwards² and \\ Thomas Aigner ${ }^{1}$ \\ ${ }^{1}$ Department of Pathology, University of Erlangen-Nürnberg, Erlangen, Germany and ${ }^{2}$ Department of \\ Laboratory Medicine and Pathology, Mayo Clinic, Rochester, MN, USA
}

\begin{abstract}
Mesenchymal chondrosarcoma is a rare, usually highly malignant chondrogenic neoplasm. The diagnosis of mesenchymal chondrosarcoma can be challenging, it nonetheless has important therapeutic and diagnostic implications. Thus, biopsies of mesenchymal chondrosarcomas without conspicuous cartilaginous differentiation cannot be safely distinguished from other small cell mesenchymal neoplasms such as Ewing's sarcoma and peripheral neuroendrocrine tumors, synovial sarcomas and hemangiopericytomas, because all of these neoplasms might show overlapping histological features, and so far, there have been no safe immunohistochemical markers available in order to differentiate these neoplasms. In our study on a large series of mesenchymal chondrosarcomas $(n=30)$ and other small cell sarcomas (Ewing's sarcomas $(n=12)$, synovial sarcomas $(n=6)$, hemangiopericytomas $(n=5)$, small cell osteosarcomas $(n=3)$, and desmoplastic small round cell tumors $(n=1)$ ), we could establish the presence of type II collagen in the extracellular tumor matrix of the small cell areas of mesenchymal chondrosarcomas as a specific and sensitive marker to identify mesenchymal chondrosarcomas and to exclude other small cell neoplasms (except chondroblastic areas in small cell osteosarcomas). In contrast, the S-100 protein was less sensitive and vimentin and total collagen content unspecific for discriminating these neoplasms. Thus, the presence of type II collagen in the extracellular tumor matrix significantly facilitates the diagnosis of mesenchymal chondrosarcomas in the absence of histologically visible chondroid matrix formation.

Modern Pathology (2005) 18, 1088-1094. doi:10.1038/modpathol.3800391; published online 25 February 2005
\end{abstract}

Keywords: mesenchymal chondrosarcoma; cartilage; extracellular matrix; collagen; diagnosis

Mesenchymal chondrosarcoma is a rare, usually highly malignant chondrogenic neoplasm. ${ }^{1-3}$ It represents about $1 \%$ of all chondrosarcomas ${ }^{1,4,5}$ and affects all ages with a peak incidence during the second decade of life. ${ }^{3}$ As a particularity of this neoplasm, about one-third of the cases develop outside the bone, including a significant number of them arising in the meninges. ${ }^{1,5-9}$ Morphologically, mesenchymal chondrosarcoma is mainly composed of two characteristic tumor components: one being

Correspondence: $\mathrm{Dr} \mathrm{T}$ Aigner, MD, DSc, Osteoarticular and Arthritis Research, Department of Pathology, University of Erlangen-Nürnberg, Krankenhausstr. 8-10, D-91054 Erlangen, Germany.

E-mail: thomas.aigner@patho.imed.uni-erlangen.de

*Both these authors contributed equally to the work.

Received 26 July 2004; revised 3 January 2005; accepted 8 January 2005; published online 25 February 2005 highly cellular and poorly differentiated and the other showing cartilage formation.

The diagnosis of mesenchymal chondrosarcoma is partially very difficult, although this has important therapeutic and diagnostic implications. ${ }^{10}$ It is rather straightforward as long as areas of cartilaginous differentiation are present. However, no safe diagnosis of mesenchymal chondrosarcoma can be made in the absence of this feature,,$^{1,9,11,12}$ and mesenchymal chondrosarcoma cannot be ruled out safely at the moment in cases of indefinite small cell mesenchymal neoplasms. In contrast, small cell epithelial neoplasms as well as hematopoietic malignancies, which might be histologically in the differential diagnosis, can safely be identified by using immunodetection of epithelial cytokeratins as well as leukocyte common antigen (CD45). Thus, the major differential diagnosis for small cell sarcomas includes-besides mesenchymal chondrosarcomas-Ewing's sarcoma-peripheral neuroendrocrine 
tumors (PNETs), synovial sarcomas, hemangiopericytomas and rhabdoid sarcoma. So far, for this distinction except for rhabdoid sarcoma, no specific markers are available. S-100 protein, a standard marker for chondrogenic neoplasms, is in mesenchymal chondrosarcomas largely negative outside the cartilaginous areas and therefore not helpful. ${ }^{11,13}$ Vimentin is partly positive, but not specific for mesenchymal chondrosarcoma. ${ }^{11}$ Recently, positivity for CD99 was reported to be a potential marker for mesenchymal chondrosarcomas. ${ }^{14}$ However, CD99 is also positive in other small cell neoplasms of the skeleton such as Ewing's sarcoma and is, thus, also not diagnostic.

In this study, we tried to evaluate whether the expression of type II collagen, a specific marker gene of physiological and neoplastic chondrocytes, ${ }^{15,16}$ which was previously shown to be expressed not just in the chondroid areas of mesenchymal chondrosarcomas, ${ }^{17}$ is of potential use for the identification of mesenchymal chondrosarcomas without overt cartilage formation. We analyzed small cell areas of a large series of mesenchymal chondrosarcomas and compared the found expression patterns with those detected in synovial sarcomas, Ewing's sarcomas and PNETs, hemangiopericytomas, small cell osteosarcomas and one case of desmoplastic small round cell tumor. Small cell epithelial neoplasms, rhabdomyosarcomas as well as hematopoietic/lymphoid malignancies can easily be ruled out by other means and were, therefore, not included in the study.

\section{Materials and methods}

\section{Tissue Preparation and Histology}

Specimens of 30 patients with diagnosed mesenchymal chondrosarcomas from the Mayo Clinic bone tumor registry and the Department of Pathology, University of Erlangen-Nürnberg, FRG, were used for the study. Additionally, 12 specimens of Ewing's sarcomas and synovial sarcomas partly showing hemangiopericytoma-like growth pattern, five cases of true hemangiopericytomas, three cases of small cell osteosarcomas and one case of desmoplastic small round cell tumor were investigated. The material was routinely fixed with $10 \%$ formalin, decalcified and embedded in paraffin. Paraffin sections (5- $\mu \mathrm{m}$ thick) were cut and stored until use at room temperature.

The histomorphology of the tumor specimens was evaluated on conventional hematoxylin and eosin (H\&E) stains.

\section{Histochemical Methods}

The total collagen content in the extracellular tumor matrix was demonstrated by Masson Goldner's trichrome stain.

\section{Immunohistochemistry}

Deparaffinized sections were enzymatically pretreated (Table 1), incubated with primary antibodies (Table 1) overnight at $4{ }^{\circ} \mathrm{C}$ and visualized using a streptavidin-biotin complex technique (Biogenex, Mainz, Germany: Super Sensitive Immunodetection System) with alkaline phosphatase as detection enzyme and 3-hydroxy-2-naphtylacid 2,4-dimethylanilid as the substrate. Nuclei were counterstained with hematoxylin.

As negative controls for immunohistochemical stainings, the primary antibodies were replaced by nonimmune mouse or rabbit serum (BioGenex; San Ramon, CA, USA) or Tris-buffered saline (pH 7.2) on control sections.

\section{Results}

\section{Histomorphology and Cytoprotein Analysis}

Histologically, the investigated neoplasms showed the typical features described in the literature according to Unni et al ${ }^{18,19}$ (Figure $1_{\mathrm{a} 1-\mathrm{c} 1}$ and $2_{\mathrm{a} 1-\mathrm{e} 1}$ ).

Cytoprotein analysis looking at the reaction for S100 protein and vimentin is given in Table 2 for each neoplasm. In short, all of the investigated neoplasms were largely positive for vimentin (Figures $1_{\mathrm{b} 2, \mathrm{c} 2}$ and $2_{\mathrm{a} 2-\mathrm{e} 2}$ ), except the mesenchymal chondrosarcomas in their matrix-poor areas (Figure $1_{\mathrm{a} 2}$ ) and some Ewing's sarcomas (Figure 2 $2_{\text {c2a }}$ ). S-100 protein was positive in mesenchymal chondrosarcomas in the chondroid areas (Figure $1_{\mathrm{c} 3}$ ), but not in the small cell areas (Figure $1_{\mathrm{a} 3}$ ) except for a very few cells in the matrix-rich areas in part of the neoplasms (6/30) (Figure $1_{\mathrm{b} 3}$ ). All other neoplasms investigated were consistently negative for S-100 protein in the tumor cells (Figure $2_{\text {аз-ез }}$ ) except the cartilagenous areas in small cell osteosarcomas (Figure $22_{\mathrm{d} 3 \mathrm{~b}}$ ).

Table 1 Primary antibodies and enzymatic pretreatments used for immunohistochemical analysis

\begin{tabular}{|c|c|c|c|c|}
\hline Antigen & Tyре & Dilution & Digestion & Source \\
\hline S-100 protein & $\mathrm{r}$ & 1:1000 & $\mathrm{P}$ & $\begin{array}{l}\text { Dako, } \\
\text { Glostrup, } \\
\text { Denmark }\end{array}$ \\
\hline Vimentin (clone V9.1) & $\mathrm{m}$ & $1: 200$ & Pt & $\begin{array}{l}\text { Dako, } \\
\text { Glostrup, } \\
\text { Denmark }\end{array}$ \\
\hline $\begin{array}{l}\text { Collagen type II } \\
\text { Novacastra, } \\
\text { Peterborough, UK }\end{array}$ & $\mathrm{r}$ & $1: 50$ & $\mathrm{H}, \mathrm{P}$ & \\
\hline
\end{tabular}

$\mathrm{H}$ : hyaluronidase (bovine testis) $(2 \mathrm{mg} / \mathrm{ml}$ (Boehringer, Mannheim, Germany), phosphate-buffered saline, $\mathrm{pH} 5,60 \mathrm{~min}$ at $37^{\circ} \mathrm{C}$ ); $\mathrm{P}$ : pronase $\left(2 \mathrm{mg} / \mathrm{ml}\right.$, phosphate-buffered saline, $\mathrm{pH} 7.3,60 \mathrm{~min}$ at $37^{\circ} \mathrm{C}$ (Boehringer, Mannheim, Germany)); Pt, protease XXIV $(0.02 \mathrm{mg} / \mathrm{ml}$, phosphate-buffered saline, $\mathrm{pH} 7.3,60 \mathrm{~min}$ at room temperature (Sigma, Berlin, Germany)); m: mouse monoclonal; r: rabbit polyclonal. 


\section{Collagen Content and Type II Collagen Immunohistochemistry}

Collagen histochemistry showed in all neoplasms more or less abundant extracellular collagen deposition with no obvious significant differences detectable except abundant extracellular matrix formation in the cartilaginous area (see Table 2). Of interest, a remarkable feature was observed in mesenchymal chondrosarcomas: the vimentin negative areas showed basically no extracellular collagenous tumor matrix.
Immunodetection for type II collagen showed, in all cases of mesenchymal chondrosarcomas, extensive extracellular type II collagen in the chondroid islands typical for this neoplasm (Figure $1_{\mathrm{c} 4}$ ). However, also the collagenous tumor matrix of the nonchondroid areas stained strongly for type II collagen (Figure $1_{\mathrm{a} 4 \mathrm{a}, \mathrm{b} 4}$ ). Only tumor areas showing histologically and histochemically no or hardly any collagenous tumor matrix were negative for type II collagen (Figure $1_{\mathrm{a} 4 \mathrm{~b}}$ ). No mesenchymal chondrosarcoma specimen was encountered, which showed no
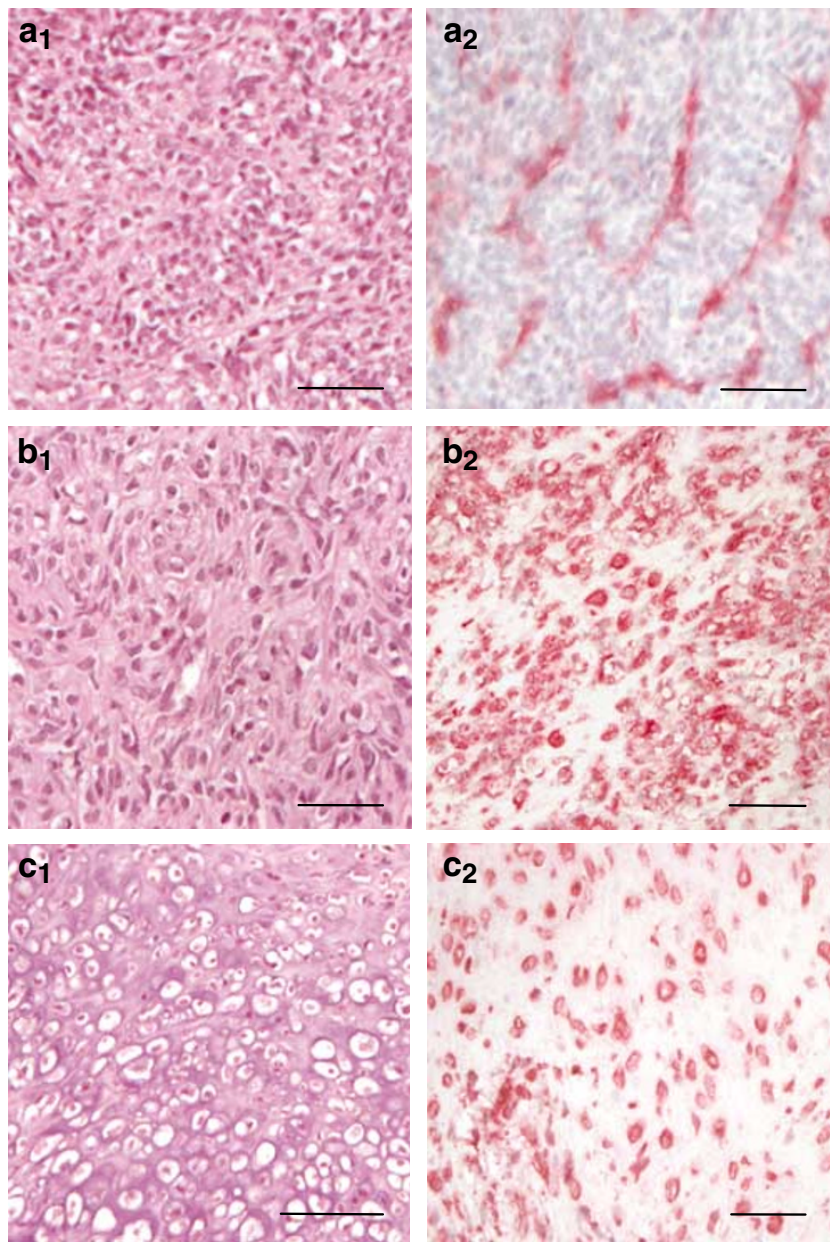
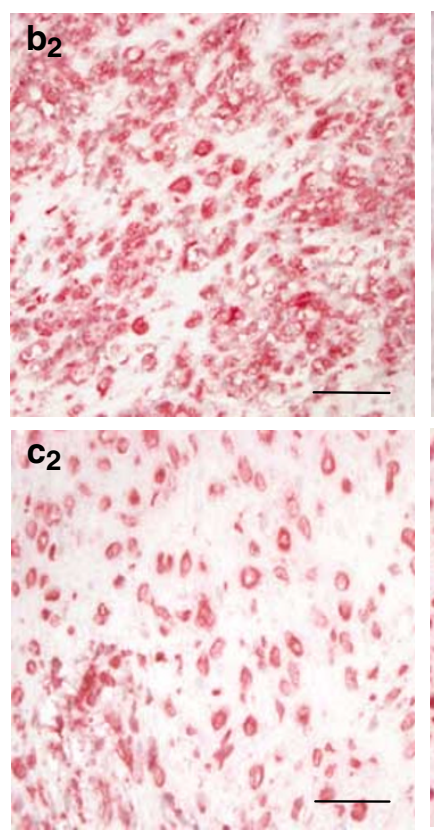
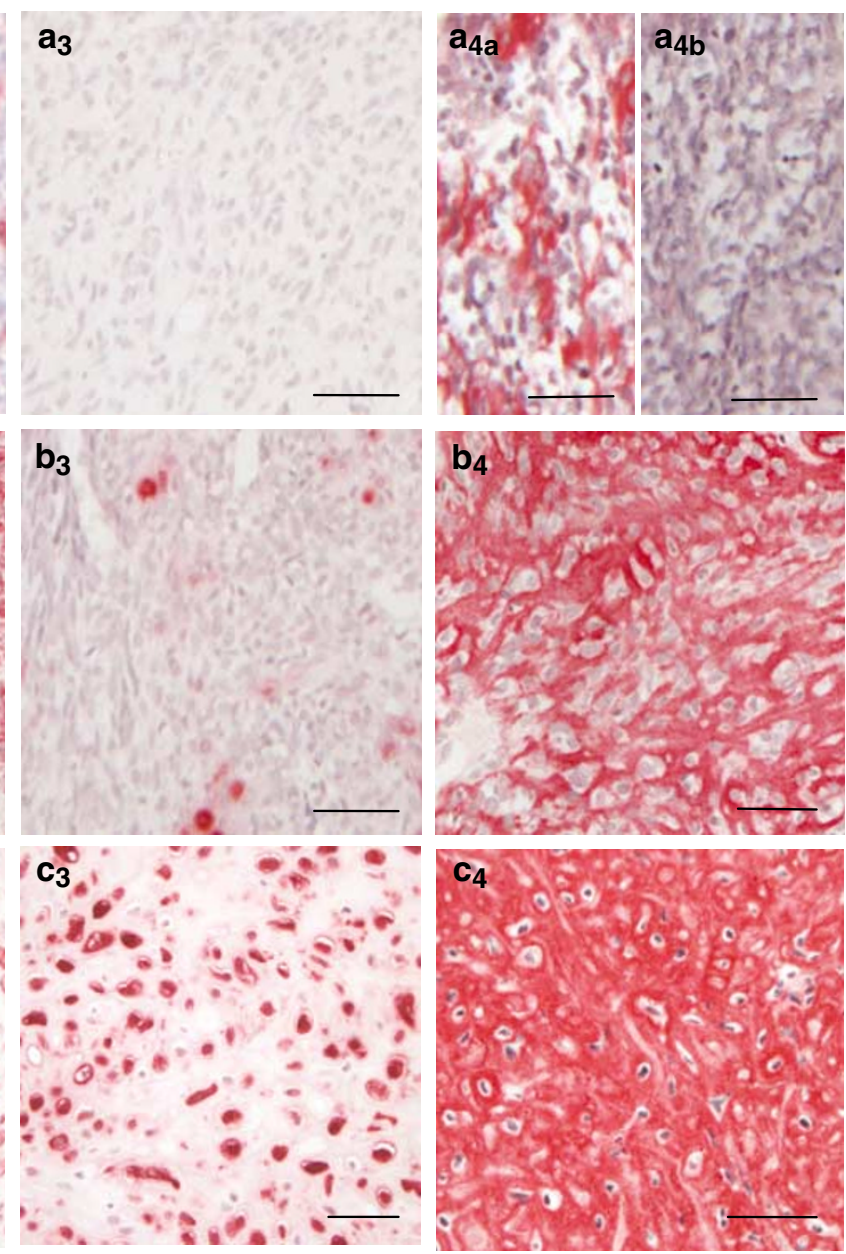

Figure 1 Representative samples of mesenchymal chondrosarcomas with undifferentiated small cell areas $\left(\mathbf{a}_{1}-\mathbf{a}_{4 \mathbf{b}}\right)$ with hardly any matrix in between the tumor cells, matrix-rich small cell areas still without any overt cartilage formation $\left(\mathbf{b}_{1}-\mathbf{b}_{\mathbf{4}}\right)$ and areas of overt cartilage formation $\left(\mathbf{c}_{\mathbf{1}}-\mathbf{c}_{\mathbf{4}}\right)$. Whereas matrix-poor small cell areas were negative for vimentin $\left(\mathbf{a}_{\mathbf{2}}\right.$ : vimentin is only positive in the vascular

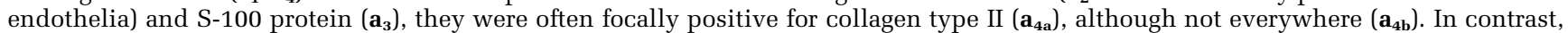
matrix-rich tumor areas were strongly positive for type II collagen $\left(\mathbf{b}_{\mathbf{4}}\right)$, whereas the positivity for S-100 was restricted to single cells $\left(\mathbf{b}_{\mathbf{3}}\right)$. Vimentin was expressed by all cells in the tumor areas $\left(\mathbf{b}_{\mathbf{2}}\right)$. In cartilagenous tumor areas, all markers investigated were positive thorughout ( $\mathbf{c}_{2}$ : vimentin; $\mathbf{c}_{3}$ : S-100 protein; $\mathbf{c}_{\mathbf{4}}$ : type II collagen). ( $\mathbf{a}_{\mathbf{1}}-\mathbf{c}_{1}$ : H\&E; $\mathbf{a}_{2}-\mathbf{c}_{2}$ : immunostaining for vimentin; $\mathbf{a}_{3}-\mathbf{c}_{3}$ : immunostaining for S-100 protein; $\mathbf{a}_{4}-\mathbf{c}_{4}$ : immunostaining for collagen type II; magnification bars: $50 \mu \mathrm{m}$ ).

Figure 2 Representative samples of synovial sarcomas $\left(\mathbf{a}_{1}-\mathbf{a}_{4}\right)$, hemangiopericytomas $\left(\mathbf{b}_{1}-\mathbf{b}_{4}\right)$, Ewing's sarcomas ( $\left.\mathbf{c}_{1}-\mathbf{c}_{4}\right)$, small cell osteosarcomas (small cell area: $\mathbf{d}_{\mathbf{1 a}}-\mathbf{d}_{\mathbf{4 a}}$; chondroblastic area: $\mathbf{d}_{\mathbf{1 b}}-\mathbf{d}_{\mathbf{4 b}}$ ) as well as desmoplastic small round cell tumor $\left(\mathbf{e}_{\mathbf{1}}-\mathbf{e}_{\mathbf{4}}\right)$. Except in chondroblastic areas of small cell osteosarcomas $\left(\mathbf{d}_{\mathbf{3}}, \mathbf{d}_{\mathbf{4 b}}\right)$, no expression of collagen type II $\left(\mathbf{a}_{4}-\mathbf{d}_{4 a}, \mathbf{e}_{4}\right)$ or of S-100 protein $\left(\mathbf{a}_{3}-\mathbf{d}_{3 a}, \mathbf{e}_{3}\right)$ within the tumor cells could be detected in any of the neoplasms investigated (including the small cell areas of small cell osteosarcomas $\left(\mathbf{d}_{\mathbf{3}}, \mathbf{d}_{4 \mathbf{a}}\right)$ ). In contrast, most neoplasms were at least in part positive for vimentin $\left(\mathbf{a}_{2}-\mathbf{e}_{2}\right)$. ( $\mathbf{a}_{1}-\mathbf{e}_{1}$ : H\&E; $\mathbf{a}_{2}-\mathbf{e}_{2}$ : immunostaining for vimentin; $\mathbf{a}_{3}-\mathbf{e}_{3}$ : immunostaining for S-100 protein; $\mathbf{a}_{4}-\mathbf{e}_{4}$ : immunostaining for collagen type II; magnification bars: $\left.50 \mu \mathrm{m}\right)$. 

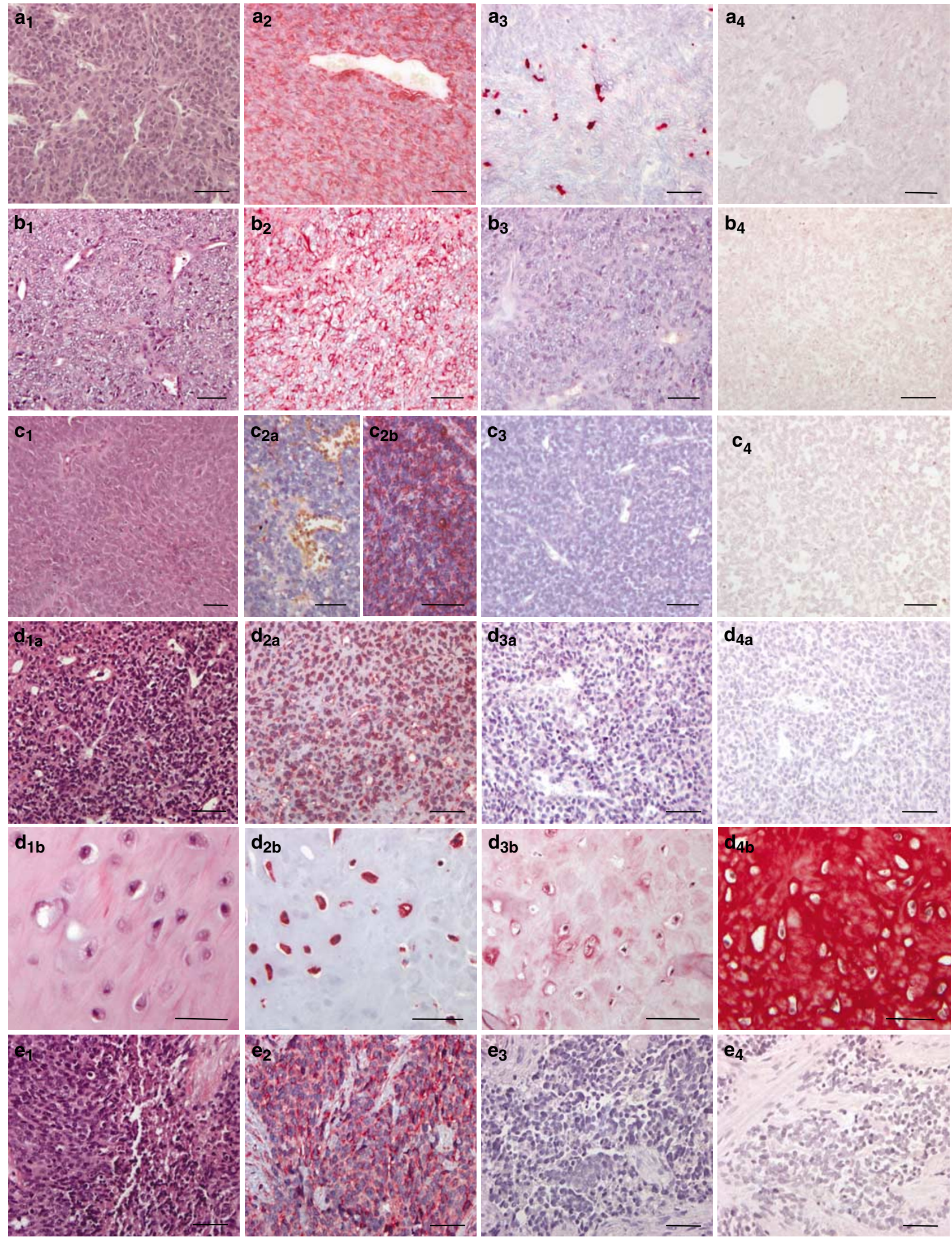
Table 2 Expression pattern of the cytoproteins vimentin and S-100 protein as well as type II collagen

\begin{tabular}{lcccc}
\hline Tumor type & Vim & S-100 & Col & II \\
\hline $\begin{array}{l}\text { Mesenchymal CS }(n=6) \\
\quad \text { Matrix-poor small cell areas }\end{array}$ & $-/+$ & - & $(+)^{\mathrm{a}}$ & $(+)^{\mathrm{a}}$ \\
$\quad$ Matrix-rich small cell areas & + & $-{ }^{\mathrm{b}}$ & ++ & ++ \\
$\quad$ Cartilaginous areas & + & + & +++ & +++ \\
Ewing's sarcoma $(n=12)$ & $+/(-)$ & - & + & - \\
Synovial sarcoma $(n=6)$ & + & - & + & - \\
Hemangiopericytoma $(n=5)$ & + & - & ++ & - \\
Small cell osteosarcoma $(n=3)$ & & & & \\
$\quad$ Small cell areas & + & - & + & - \\
$\quad$ Cartilaginous areas & + & + & +++ & ++ \\
Desmoplastic small round & $+/-$ & - & ++ & - \\
$\quad$ cell tumor $(n=1)$ & & & & \\
\hline
\end{tabular}

${ }^{\mathrm{a}}$ Focally positive.

${ }^{\mathrm{b}}$ Except single rounded cells.

Additionally, the presence of collagen (Col) as determined by histochemistry is listed.

type II collagen positive extracellular tumor matrix in any part of the specimens.

All other investigated small cell neoplasms were completely negative for type II collagen in the small cell areas (Figure $2_{\mathrm{a} 4-\mathrm{e} 4}$ ). The only positivity was observed in areas of overt cartilage formation in the small cell osteosarcomas (Figure $2_{\mathrm{d} 4 \mathrm{~b}}$ ), whereas the small cell areas were also completely negative in these neoplasms (Figure $2_{\mathrm{d} 4 \mathrm{a}}$ ).

\section{Discussion}

Mesenchymal chondrosarcomas are so far very difficult to diagnose with certainty if no overt cartilaginous differentiation is visible in the tissue specimen, which is in particular possible with small biopsy specimens. ${ }^{9,11,12}$ In this situation, other mesenchymal neoplasms such as Ewing's sarcoma, hemangiopericytoma, and synovial sarcoma, and small cell osteosarcomas come into the differential diagnosis; they might at least be possible, in part, to be identified by chromosomal rearrangement analysis, but this is mostly restricted to synovial sarcomas and Ewing's sarcomas and the technology is not available on a wide-spread basis. Nonmesenchymal small cell malignancies, especially malignant lymphomas and metastatic carcinomas, do not present practical problems, because simple immunohistochemical markers, such as common leukocyte antigen and epithelial cytokeratins, can identify these neoplasms and are negative in mesenchymal chondrosarcomas. ${ }^{11,18,20}$ Also, neuroblastomas and embryonal rhabdomyosarcomas are readily distinguishable using S-100 protein and actin and desmin as molecular markers, respectively. ${ }^{12}$

The distinction, however, from other mesenchymal small cell neoplasms is of major clinical interest as it implicates different treatment protocols as well as a different prognosis. ${ }^{14}$ Thus, the 10 -year survival rate after adequate treatment of Ewing's sarcoma is greater than $70 \%$ whereas it is less than $30 \%$ for mesenchymal chondrosarcomas. ${ }^{14}$ This is in particular important, because many of the small cell neoplasms including mesenchymal chondrosarcomas tend to affect younger people. ${ }^{3}$

It is well established that mesenchymal chondrosarcoma consists of basically two tissue types. Besides the histologically identifiable and diagnostic cartilaginous areas, areas composed of small and poorly differentiated cells may represent a high portion of the neoplasm. These small cells largely lack S-100 protein expression, which is one widely used marker for chondrocytic differentiation within neoplasms. ${ }^{21,22}$ This is the reason why S-100 protein cannot be used to identify mesenchymal chondrosarcoma if there are no chondroid islands present, a feature largely confirmed in this study. ${ }^{21-24} \mathrm{~A}$ potential, but rather rare, indicator of mesenchymal chondrosarcoma are single large rounded cells, which are positive for S-100 protein. ${ }^{20,25}$ Of note, these cells are always surrounded by an extracellular matrix positive for collagen type II. $^{25}$ The staining pattern for vimentin is also not per se helpful for the distinction from other mesenchymal small cell neoplasms, although vimentin-negative areas in a nonepithelial small cell neoplasms is suggestive of mesenchymal chondrosarcoma, in particular, if no or hardly any pericellular (collagenous) matrix is detectable. Also, other investigated markers showed a very inconclusive picture of expressed phenotypes in the small cell compartment. Thus, some studies found positivity for NSE, GFAP, Leu-7, factor-VIII, and even desmin and cytokeratins in some cases whereas others did not. ${ }^{11,20}$ Recently, positivity for CD99 was reported to be a potential marker for mesenchymal chondrosarcomas. ${ }^{14,26}$ However, CD99 is also positive in other small cell neoplasms of the skeleton such as Ewing's sarcoma. ${ }^{27}$ SOX9, one key transcription factor involved in fetal chondrogenesis, ${ }^{28}$ was recently suggested to allow distinction of mesenchymal chondrosarcomas from other small cell neoplasms. ${ }^{29}$ Clearly, this might be another suitable approach as soon as a reliable antibody is commercially available.

Type II collagen is a selective marker for chondrocytic cell differentiation and, therefore, characteristic for chondrogenic neoplasms. ${ }^{15,16}$ The alternative splice variant of collagen type II, COL2A, which is also recognized by antibodies against conventional type II collagen, identifies chondroprogenitor cells, ${ }^{30}$ which represent the dominant small cell population in mesenchymal chondrosarcomas. ${ }^{17}$ Our study clearly demonstrates that the detection of type II collagen in the extracellular tumor matrix is a sensitive marker for the identification of mesenchymal chondrosarcomas among small cell tumors within and outside the bone. All other 
mesenchymal small cell neoplasms, which come by mere histology into differential diagnosis, did not show any presence of collagen type II at least in the small cell areas. Instead, one has to expect that small cell osteosarcomas should specifically show deposition of type I collagen, the major protein of bone matrix. One potential limitation is that the total lack of tumor matrix formation can result in the absence of type II collagen. In these areas, the tumor cells are, however, also negative for vimentin, hinting to the correct diagnosis, although other neoplasms such as Ewing's sarcomas may be partly negative. A second caveat is that cartilage formation secondary to fracturing should not be misinterpreted as neoplastic type II collagen production. Obviously, overtly cartilagenous areas in small cell osteosarcomas are positive for type II collagen similar to conventional chondroblastic osteosarcomas (own unpublished observation); however, the small cell areas were negative.

Overall, our study suggests that immunostaining for collagen type II might be used in any unclear cases of small cell skeletal and nonskeletal neoplasms. Type II collagen allows the identification of mesenchymal chondrosarcomas that lack overt cartilage formation, particularly in small biopsy specimens. It is, thus, a helpful additional tool for the diagnosis of small cell mesenchymal malignancies.

\section{Acknowledgements}

We are grateful for the excellent technical assistance of Mrs S Fickenscher and O Reimer. This work was supported by the Wilhelm-Sander-Stiftung (Munich, FRG; Grants 96.050).

\section{References}

1 Salvador AH, Beabout JW, Dahlin DC. Mesenchymal chondrosarcoma-observations on 30 new cases. Cancer 1971;28:605-615.

2 Bertoni F, Picci P, Bacchini P, et al. Mesenchymal chondrosarcoma of bone and soft tissues. Cancer 1983;52:533-541.

3 Dabska M, Huvos AG. Mesenchymal chondrosarcoma in the young. A clinicopathological study of 19 patients with explanation of histogenesis. Virchows Arch 1983;399:89-104.

4 Huvos AG, Rosen G, Dabska M, et al. Mesenchymal chondrosarcoma-A clinicopathologic analysis of 35 patients with emphasis on treatment. Cancer 1983;51:1230-1237.

5 Nakashima Y, Unni KK, Shives TC, et al. Mesenchymal chondrosarcoma of bone and soft tissue-a review of 111 cases. Cancer 1986;57:2444-2453.

6 Guccion JG, Font RL, Enzinger FM, et al. Extraskeletal mesenchymal chondrosarcoma. Arch Pathol 1973;95:336-340.

7 Rollo JL, Green WR, Kahn LB. Primary meningeal mesenchymal chondrosarcoma. Arch Pathol Lab Med 1979;103:239-243.
8 Seth HN, Singh M. Intracranial mesenchymal chondrosarcoma. Acta Neuropathol 1973;24:86-89.

9 Scheithauer BW, Rubinstein LJ. Meningeal mesenchymal chondrosarcoma. Cancer 1978;42:2744-2752.

10 Peydro-Olaya A, Llombart-Bosch A, Carda-Batalla C, et al. Electron microscopy and other ancillary techniques in the diagnosis of small round cell tumor. Semin Diagn Pathol 2003;20:25-45.

11 Swanson PE, Lillemoe TJ, Manivel JC, et al. Mesenchymal chondrosarcoma. Arch Pathol Lab Med 1990;114:943-948.

12 Dickersin GR, Rosenberg AE. The ultrastructure of small-cell osteosarcoma, with a review of the light microscopy and differential diagnosis. Hum Pathol 1991;22:267-275.

13 Dorfman HD, Czerniak B. Bone Tumors. Mosby: St Louis, 1998.

14 Granter SR, Renshaw AA, Flechter CDM, et al. CD99 reactivity in mesenchymal chondrosarcoma. Hum Pathol 1996;27:1273-1276.

15 Aigner T, Dertinger S, Belke J, et al. Chondrocytic cell differentiation in clear cell chondrosarcoma. Hum Pathol 1996;27:1301-1305.

16 Aigner T, Dertinger S, Vornehm SI, et al. Phenotypic diversity of neoplastic chondrocytes and extracellular matrix gene expression in cartilaginous neoplasms. Am J Pathol 1997;150:2133-2141.

17 Aigner T, Loos S, Müller S, et al. Cell differentiation and matrix gene expression in mesenchymal chondrosarcomas. Am J Pathol 2000;156:1327-1335.

18 Unni KK. Dahlin's Bone Tumors, 5th edn. LippincottRaven: Philadelphia-New York, 1996.

19 Fletcher CDM, Unni KK, Mertens F (eds). Tumors of Soft Tissue and Bone. IARCPress: Lyon, 2002.

20 Rushing EJ, Armonda RA, Ansari Q, et al. Mesenchymal chondrosarcoma. A clinicopathologic and flow cytometric study of 13 cases presenting in the central nervous system. Cancer 1996;77:1884-1891.

21 Monda L, Wick MR. S-100 protein immunostaining in the differential diagnosis of chondroblastoma. Hum Pathol 1985;16:287-293.

22 Okajima K, Honda I, Kitagawa T. Immunohistochemical distribution of S-100 protein in tumors and tumorlike lesions of bone and cartilage. Cancer 1988;61: 792-799.

23 Weiss A-PC, Dorfman HD. S-100 protein in human cartilage lesions. J Bone Joint Surg 1986;68-A:521-526.

24 Nakamura Y, Becker LE, Marks A. S-100 protein in tumors of cartilage and bone. Cancer 1983;52: 1820-1824.

25 Ushigome-S, Takakuwa T, Shinagawa T, et al. Ultrastructure of cartilaginous tumors and S-100 protein in the tumors. With reference to the histogenesis of chondroblastoma, chondromyxoid fibroma and mesenchymal chondrosarcoma. Acta Pathologica Japonica 1984;34:1285-1300.

26 Fellinger EJ, Garin-Chesa P, Triche TJ, et al. Immunohistochemical analysis of Ewings sarcoma cell surface antigen p30/32 $2^{\mathrm{MIC} 2}$. Am J Pathol 1991;139:317-325.

27 Folpe AL, Hill CE, Parham DM, et al. Immunohistochemical detection of FLI-1 protein expression: a study of 132 round cell tumors with emphasis on CD99positive mimics of Ewing's sarcoma/primitive neuroectodermal tumor. Am J Surg Pathol 2000;24: 1657-1662.

28 Bi W, Deng JM, Zhang Z, et al. Sox9 is required for cartilage formation. Nat Genet 1999;22:89. 
29 Wehrli BM, Huang $\mathrm{W}$, de Crombrugghe $\mathrm{B}$, et al. Sox9, a master regulator of chondrogenesis, distinguishes mesenchymal chondrosarcoma from other small blue round cell tumors. Hum Pathol 2003;34: 263-269.
30 Sandell LJ, Morris NP, Robbins JR, et al. Alternatively spliced type II procollagen mRNAs define distinct populations of cells during vertebral development: differential expression of the amino-propeptide. J Cell Biol 1991;114:1307-1319. 